\title{
Compostos químicos e aspectos botânicos, etnobotânicos e farmacológicos da Byrsonima verbascifolia Rich ex. A. Juss
}

SALDANHA, A.A.'; SOARES, A.C. ${ }^{*}$

'Programa de Pós-Graduação em Ciências Farmacêuticas da Universidade Federal de São João del-Rei (UFSJ), Campus Centro-Oeste Dona Lindu.- Rua Sebastião Gonçalves Coelho, 400, Bairro Chanadour- Divinópolis, MG, CEP: 35.5014-296. 'Autor para correspondência: adrianasouza@ufsj.edu.br

RESUMO: Byrsonima verbascifolia Rich ex. A. Juss é uma espécie do cerrado brasileiro com uso etnobotânico vasto. O objetivo desse trabalho foi realizar um levantamento bibliográfico de artigos originais e revisões, indexados até agosto de 2014 nas bases de dados Periódicos CAPES, Scielo, Scopus, Web of Science e Medline, nos idiomas português e inglês, utilizando a palavra-chave Byrsonima verbascifolia. Foram contemplados a composição química e os aspectos botânicos, etnobotânicos e farmacológicos. Os estudos presentes na literatura avaliaram as atividades antioxidante, antifúngica, antiviral, antimicrobiana, moluscicida, antimutagênica, mutagênica, teratogênica, imunomodulatória, tóxica e citotóxica de extratos dessa espécie. Apenas um estudo avaliou a atividade da Byrsonima verbascifolia Rich ex. A. Juss in vivo, sendo comprovado que o extrato hidrometanólico das folhas não induz teratogênese, mutagênese ou efeito estimulante ou depressor da resposta imune. Metodologias in vitro predominaram o que demonstra a necessidade de investigação científica empregando testes in vivo para a melhor avaliação das outras atividades biológicas mencionadas.

Palavras-chave: Byrsonima verbascifolia, murici, anti-inflamatório, compostos químicos, atividades farmacológicas.

\begin{abstract}
Chemical compounds and botanical, ethnobotanical and pharmacological aspects of Byrsonima verbascifolia Rich ex. A. Juss. Byrsonima verbascifolia is a species of Brazilian cerrado with extensive ethnobotanical application. The aim of this study was to perform a bibliographic description of original papers and reviews indexed until August 2014 in the databases of the CAPES Digital Library, Scielo, Scopus, Web of Science and Medline, written in Portuguese and English, using the keyword Byrsonima verbascifolia. The chemical and botanical compositions and the ethnobotanical and pharmacological aspects were contemplated. The researches in the reports evaluated the antioxidant, antifungal, antiviral, antimicrobial, molluscicide, antimutagenic, mutagenic, teratogenic, immunomodulatory, toxic and cytotoxic activities of the extracts of this specie. Only one study evaluated the in vivo activity of the Byrsonima verbascifolia Rich ex. A. Juss and proved that the hydromethanolic extract from the leaves does not induce teratogenesis, mutagenesis, stimulant or depressant effect of the immune response. The In vitro methodologies represented the higher number of researches demonstrating the need of scientific investigation using in vivo tests for better assessment of other biological activities mentioned.
\end{abstract}

Keywords: Byrsonima verbascifolia, murici, anti-inflammatory, chemical compounds, pharmacological activities.

\section{INTRODUÇÃO}

A família Malpighiaceae possui distribuição tropical e subtropical sendo representada por 75 gêneros e 1.300 espécies. No território brasileiro ocorrem 38 gêneros e cerca de 300 espécies. Uma característica comum dessa família é a presença de nectários extraflorais, dispostos aos pares nas bases das sépalas da maioria das espécies (Souza \& Lorenzi, 2008). Destaca-se pelo elevado potencial econômico, como fonte de produtos alimentícios, medicinais, madeireiros e ornamentais (Ribeiro et 
al., 1999).

Um dos maiores gêneros da família Malpighiaceae é o Byrsonima, possuindo 150 espécies com distribuição marcadamente neotropical (Mabberley, 1993). O Brasil concentra cerca de 50\% das espécies nas regiões Norte, Nordeste e Central, podendo também ser encontradas na região Sudeste do país, em áreas do cerrado. Essas espécies são conhecidas popularmente no Brasil como "muricis" (murici da várzea, murici da mata, murici-amarelo, dentre outros), sendo diferenciadas pela cor de suas flores e frutos, ou pelo local de ocorrência (Guilhon-Simplicio \& Pereira, 2011) e são comumente empregadas na medicina popular (Sannomiya et al., 2005).

Especificamente a espécie Byrsonima verbascifolia Rich ex. A. Juss é largamente utilizada na medicina tradicional, em diversas regiões do Brasil, para o tratamento das mais variadas condições como: febre (Almeida et al., 1998), infecção, inflamação e diarreia (Panizza, 1998).

Muitos povos descrevem desde os tempos mais remotos a utilização de plantas medicinais para o tratamento, cura e prevenção de doenças (Mengue et al., 2001). Segundo dados da Organização Mundial de Saúde, o uso de plantas medicinais é a principal opção terapêutica de cerca de $80 \%$ da população no mundo (Brasil, 2006).

O uso etnobotânico despertou a necessidade da avaliação da eficácia e segurança das espécies vegetais (Mengue et al., 2001). Com o advento da pesquisa científica, em torno do século XIX, diversas substâncias puderam ser isoladas das plantas e serviram de modelos para a produção de fármacos, o que atualmente representa uma proporção substancial do mercado global de medicamentos (Yunes et al., 2001). As plantas medicinais representam importante fonte de fármacos devido ao elevado número de moléculas com potencial terapêutico, podendo contribuir efetivamente na busca de novos produtos bioativos (Wang \& Ng, 1999; Coon \& Ernst, 2003; Moll, 2006).

Considerando o extenso uso etnofarmacológico da Byrsonima verbascifolia Rich ex. A. Juss e o crescente interesse econômico pela espécie, o presente trabalho teve como objetivo revisar os principais aspectos botânicos, etnobotânicos, químicos e farmacológicos descritos na literatura. Pesquisas relacionadas às atividades farmacológicas e toxicológicas de espécies vegetais reforçam a preservação de plantas medicinais bem como à utilização racional, eficaz e segura de fitoterápicos (Agra,1982; Yunes et al., 2001).

\section{Fonte de dados}

Para a realização desse trabalho buscou-se artigos originais e revisões indexados até agosto de
2014 nas bases Periódicos CAPES, Scielo, Scopus, Web of Science e Medline. Para a busca foi utilizada a palavra-chave Byrsonima verbascifolia. Não foi utilizada restrição em relação ao ano da publicação.

\section{Descrição botânica}

Byrsonima verbascifolia Rich ex. A. Juss (Malpighiaceae) é popularmente conhecida como "murici" (Morais et al., 2013), "murici-cascudo", "mirici", "douradinha-falsa","muricizinho", "orelha-de-burro", "orelha-de-veado", "semaneira", "baga-de-tucano" (Mendanha et al., 2010). Possui hábito subarbustivo (Barbosa et al., 2005) e folhas grandes e rígidas (Andrade et al., 1995), com pêlos em ambas faces (Andrade et al., 1995; Andrade et al., 1999). O fruto dessa espécie possui coloração amarela (Guimarães \& Silva, 2008; Alberto et al., 2011), diâmetro entre 1,50 à $2 \mathrm{~cm}$ com cheiro forte semelhante a queijo rançoso (Guimarães \& Silva, 2008), sabor azedo e ligeiramente oleoso (Araújo et al., 2009). A madeira possui coloração amarelada ou avermelhada e brilhante (Alberto et al., 2011).

\section{Distribuição e ocorrência}

Byrsonima verbascifolia Rich ex. A. Juss é uma espécie típica do cerrado brasileiro com elevada densidade no Centro-Oeste e Norte do Brasil (Barbosa \& Fearnside, 2004; Barbosa et al., 2005) e com baixa biomassa (Barbosa \& Fearnside, 2004). A produção de frutos nesta espécie ocorre de dezembro a março, nas regiões serranas do Sudeste nos cerrados do Mato Grosso e Goiás e litoral do Norte e Nordeste do Brasil (Guimarães \& Silva, 2008).

\section{Usos etnobotânicos}

Os usos etnobotânicos da Byrsonima verbascifolia Rich ex. A. Juss incluem: uso de infusão, preparada a partir das folhas para o tratamento de diarreia, infecção intestinal e proteção da mucosa intestinal. Infusão das raízes para o tratamento de feridas crônicas, doença de Chagas, inflamação da cavidade oral e da garganta e do trato genital feminino. A casca possui propriedade laxante e ação antipirética. $O$ fruto, quando consumido com açúcar, é também um laxante moderado e pode ser utilizado para o tratamento do processo inflamatório nos brônquios e como antitussígeno (Guilhon-Simplicio \& Pereira, 2011).

\section{Outras aplicações}

O fruto da Byrsonima verbascifolia Rich ex. A. Juss é comercializado em feiras e mercados locais. A polpa é carnuda e macia (Guimarães \& Silva, 2008) sendo consumida in natura (Guimarães \& Silva, 2008; Alberto et al., 2011; Nascimento \& PenteadoDias, 2011) ou como suco (Guimarães \& Silva, 2008; Alberto et al., 2011), geleia, sorvete, licor (Guimarães

Rev. Bras. PI. Med., Campinas, v.17, n.4, supl. II, p.1000-1006, 2015. 
\& Silva, 2008; Araújo et al., 2009; Alberto et al., 2011) e conserva (Alberto et al., 2011). A porção não comestível representa $46,50 \%$ do fruto (Guimarães \& Silva, 2008). A madeira é adequada para construção e também pode ser utilizada no curtume $(15-20 \%$ de tanino). Além disso, indústrias utilizam a tinta preta extraída da casca dessa espécie para o tingimento do algodão (Alberto et al., 2011).

\section{Composição química}

Os compostos $\beta$-amirina, $\beta$-amirirona, $\beta$-sitosterol, 3-O-acetil-lupeol, ácido 3-O-acetiloleanólico, friedelina e triterpenos foram identificados na casca do caule da Byrsonima verbascifolia Rich ex. A. Juss (Gottlieb et al., 1975; Guilhon-Simplicio \& Pereira, 2011). Outros compostos encontrados nas folhas dessa espécie são $\alpha$-amirina, ácido oleanólico, ácido ursólico, quercetina, quercetina-3-O- $\alpha$-Larabinopiranosídeo (guaijaverina), quercetina-3-O- $\beta$ D-glicopiranosídeo (isoquercetina) (Guilhon-Simplicio \& Pereira, 2011; Gonçalves et al., 2013), bem como, taninos, triterpenos (Cecílio et al., 2012), derivados gálicos, catequínicos e epicatequínicos (Gonçalves et al., 2013), saponinas (Cecílio et al., 2012; Gonçalves et al., 2013) e cumarinas (Cecílio et al., 2012). A polpa do fruto dessa espécie possui $\beta$-caroteno, ácido ascórbico, $\alpha$-tocoferol e $\beta$-tocotrienol (Hamacek et al., 2014).

\section{Potencial farmacológico}

As atividades antioxidante, antifúngica, antiviral, antimicrobiana, moluscicida, antimutagênica, mutagênica, teratogênica, imunomodulatória, tóxica e citotóxica de extratos da Byrsonima verbascifolia Rich ex. A. Juss foram avaliadas através de estudos principalmente in vitro.

Os resultados do estudo realizado por Cecílio et al. (2012), demonstram que não houve a amplificação do material genético do rotavírus por RTPCR em células do rim de macaco rhesus (MA-104) pré-tratadas com o extrato etanólico obtido das folhas $(500 \mu \mathrm{g} / \mathrm{mL})$ dessa espécie. Dessa forma, sugere-se a presença de compostos bioativos capazes de inibir a replicação viral.

Espanha et al. (2014), demonstraram que o extrato hidroalcoólico obtido das folhas de $B$. verbascifolia Rich ex. A. Juss possui um potencial como agente protetor contra mutágenos indiretos que requerem ativação metabólica. Nessa espécie há elevada concentração de catequinas que conhecidamente possuem ação antimutagênica (Espanha et al., 2014).

Naruzawa \& Papa (2011), concluíram que o extrato hidroetanólico das folhas da $B$. verbascifolia Rich ex. A. Juss apresentou uma maior atividade antifúngica em relação ao extrato aquoso.

No estudo realizado por Lopez et al. (2001), foi demonstrado que o extrato metanólico das folhas da $B$. verbascifolia Rich ex. A. Juss possui uma excelente atividade antiviral contra o vírus herpes simplex tipo 1, com uma concentração inibitória mínima muito baixa $(2,50 \mu \mathrm{g} / \mathrm{mL})$.

Mendanha et al. (2010), acreditam que o efeito antimutagênico do extrato aquoso obtido das folhas dessa espécie pode estar relacionado com a presença de flavonóides, terpenos e taninos.

Fatores como o tipo de extrato, parte da planta utilizada bem como a metodologia empregada podem resultar em diferentes perfis de atividades biológicas (Falcão et al., 2005). A tabela 1 descreve as várias atividades farmacológicas, avaliadas utilizando metodologias in vitro, de diferentes extratos da $B$. verbascifolia Rich ex. A. Juss, sendo classificados em ativos e inativos.

O único estudo realizado in vivo comprovou que o extrato hidrometanólico das folhas da $B$. verbascifolia Rich ex. A. Juss não induz teratogênese, mutagênese ou efeito estimulante ou depressor da resposta imune (tabela 2). A avaliação da teratogenicidade foi realizada em camundongos Swiss fêmeas tratadas com o extrato dessa espécie em diferentes períodos da gravidez, com o intuito de analisar uma possível interferência no desenvolvimento embrio-fetal (Gonçalves et al., 2013).

\section{CONCLUSÃO}

Verificamos com o levantamento bibliográfico realizado que a Byrsonima verbascifolia Rich ex. A. Juss é uma espécie com hábito subarbustivo e nativa do cerrado brasileiro. Com relação ao aspecto etnobotânico um importante uso da espécie é como anti-inflamatório. A composição química da espécie foi avaliada na casca do caule, folhas e polpa do fruto sendo os compostos terpênicos e fenólicos as principais classes de metabólitos secundários identificadas. Apesar da importância etnobotânica dessa espécie estudos científicos que comprovem os efeitos farmacológicos são escassos. O desenvolvimento de estudos científicos nesse contexto é necessário para a validação do uso popular e também para a segurança no uso terapêutico. Além disso, a maioria dos poucos estudos a respeito dessa espécie foram realizados in vitro. Metodologias que utilizam testes in vitro possuem como desvantagem não reproduzir fielmente a complexidade de um organismo vivo, sendo difícil correlacionar seus resultados com a clínica (Barcelos et al., 2008). Dessa forma, a realização de estudos para a investigação dos efeitos farmacológicos, principalmente in vivo, é essencial para a validação do uso clínico e também para o desenvolvimento tecnológico de novos fármacos. 
TABELA 1. Atividades farmacológicas de diferentes extratos obtidos da Byrsonima verbascifolia Rich ex. A. Juss, avaliadas in vitro.

\begin{tabular}{|c|c|c|c|c|c|c|c|}
\hline $\begin{array}{l}\text { Parte } \\
\text { usada }\end{array}$ & $\begin{array}{l}\text { Atividade } \\
\text { avaliada }\end{array}$ & Extrato & Concentração & Modelo & Resultado & & Referência \\
\hline Folhas & Antifúngica & Diclorometânico & $10 \mathrm{mg} / \mathrm{mL}$ & $\begin{array}{l}\text { Bioautografia } \\
\text { com esporos de } \\
\text { Cladosporium } \\
\text { sphaerospermum }\end{array}$ & Inativo & & $\begin{array}{l}\text { Alves et al., } \\
2000\end{array}$ \\
\hline \multirow[t]{4}{*}{ Folhas } & \multirow[t]{4}{*}{ Antimicrobiana } & \multirow[t]{4}{*}{ Diclorometânico } & \multirow{4}{*}{$\begin{array}{l}5 \mathrm{mg} \text { do extrato } \\
\text { dissolvido no meio } \\
\text { de cultura }\end{array}$} & \multirow[t]{4}{*}{ Difusão em ágar } & Bacillus cereus & Ativo & \multirow{4}{*}{$\begin{array}{l}\text { Alves et al., } \\
2000\end{array}$} \\
\hline & & & & & Escherichia coli & Inativo & \\
\hline & & & & & Staphylococcus aureus & Ativo & \\
\hline & & & & & Pseudomonas aeruginosa & Ativo & \\
\hline Folhas & Moluscicida & Diclorometânico & $\begin{array}{l}\text { Concentração inicial } \\
\text { de } 100 \text { ppm }\end{array}$ & $\begin{array}{l}\text { Teste com } \\
\text { Biomphalaria } \\
\text { glabrata após } 24 \mathrm{~h} \text { de } \\
\text { exposição }\end{array}$ & Ativo & & $\begin{array}{l}\text { Alves et al., } \\
2000\end{array}$ \\
\hline Folhas & Tóxica & Diclorometânico & $1 ; 10 ; 100 \mu \mathrm{g} / \mathrm{mL}$ & $\begin{array}{l}\text { Teste de letalidade } \\
\text { utilizando Artemia } \\
\text { salina }\end{array}$ & Inativo (não apresentou toxi & cidade) & $\begin{array}{l}\text { Alves et al., } \\
2000\end{array}$ \\
\hline Folhas & Citotóxica & Metanólico & $\begin{array}{l}\text { Concentração inicial } \\
\text { de } 2000 \mu \mathrm{g} / \mathrm{mL}\end{array}$ & $\begin{array}{l}\text { Monocamadas } \\
\text { de células Vero } \\
\text { cultivadas em } \\
\text { microplacas }\end{array}$ & Inativo (não apresentou efei & to citotóxico) & $\begin{array}{l}\text { Lopez et } \\
\text { al., } 2001\end{array}$ \\
\hline \multirow[t]{2}{*}{ Folhas } & \multirow[t]{2}{*}{ Antiviral } & \multirow[t]{2}{*}{ Metanólico } & \multirow{2}{*}{$\begin{array}{l}\text { Concentração inicial } \\
\text { de } 2000 \mu \mathrm{g} / \mathrm{mL}\end{array}$} & \multirow{2}{*}{$\begin{array}{l}\text { Concentração mínima } \\
\text { inibitória }\end{array}$} & Vírus herpes simplex tipo 1 & Ativo & \multirow{2}{*}{$\begin{array}{l}\text { Lopez et } \\
\text { al., } 2001\end{array}$} \\
\hline & & & & & Poliovírus & Inativo & \\
\hline \multirow[t]{8}{*}{ Folhas } & \multirow[t]{8}{*}{ Antimicrobiana } & \multirow[t]{8}{*}{ Metanólico } & \multirow[t]{8}{*}{$100 \mathrm{mg} / \mathrm{mL}$} & \multirow[t]{8}{*}{ Teste de disco-difusão } & Bacillus subtilis & Ativo & \multirow{8}{*}{$\begin{array}{l}\text { Lopez et } \\
\text { al., } 2001\end{array}$} \\
\hline & & & & & Streptococcus faecalis & Ativo & \\
\hline & & & & & $\begin{array}{l}\text { Staphylococcus aureus } \\
\text { K147 meticilina-sensível }\end{array}$ & Ativo & \\
\hline & & & & & Escherichia coli DC10 & Inativo & \\
\hline & & & & & Klebsiella pneumoniae & Inativo & \\
\hline & & & & & $\begin{array}{l}\text { Pseudomonas aeruginosa } \\
187\end{array}$ & Inativo & \\
\hline & & & & & Salmonella typhimurium & Inativo & \\
\hline & & & & & Mycobacterium phlei & Ativo & \\
\hline Folhas & Antifúngica & Metanólico & $100 \mathrm{mg} / \mathrm{mL}$ & Teste de disco-difusão & Candida albicans & Inativo & $\begin{array}{l}\text { Lopez et } \\
\text { al., } 2001\end{array}$ \\
\hline \multirow[t]{4}{*}{ Folhas } & \multirow[t]{4}{*}{ Antifúngica } & \multirow[t]{4}{*}{ Aquoso } & \multirow[t]{4}{*}{$\begin{array}{l}50 \% \text { da } \\
\text { concentração } \\
\text { relativa do volume }\end{array}$} & $\begin{array}{l}\text { Crescimento micelial } \\
\text { de Corynespora } \\
\text { cassiicola }\end{array}$ & $\begin{array}{l}\text { Inativo (houve na verdade u } \\
\text { do crescimento micelial) }\end{array}$ & m estímulo & \multirow[t]{4}{*}{$\begin{array}{l}\text { Naruzawa } \\
\text { \& Papa, } \\
2011\end{array}$} \\
\hline & & & & $\begin{array}{l}\text { Crescimento micelial } \\
\text { de Colletotrichum } \\
\text { gloeosporioides }\end{array}$ & Ativo & & \\
\hline & & & & $\begin{array}{l}\text { Germinação } \\
\text { do esporo de } \\
\text { Corynespora } \\
\text { cassiicola }\end{array}$ & Ativo & & \\
\hline & & & & $\begin{array}{l}\text { Germinação } \\
\text { do esporo de } \\
\text { Colletotrichum } \\
\text { gloeosporioides }\end{array}$ & Ativo & & \\
\hline \multirow[t]{4}{*}{ Folhas } & \multirow[t]{4}{*}{ Antifúngica } & \multirow[t]{4}{*}{ Hidroetanólico } & \multirow[t]{4}{*}{$\begin{array}{l}50 \% \text { da } \\
\text { concentração } \\
\text { relativa do volume }\end{array}$} & $\begin{array}{l}\text { Crescimento micelial } \\
\text { de Corynespora } \\
\text { cassiicola }\end{array}$ & Ativo & & \multirow[t]{4}{*}{$\begin{array}{l}\text { Naruzawa } \\
\& \text { Papa, } \\
2011\end{array}$} \\
\hline & & & & $\begin{array}{l}\text { Crescimento micelial } \\
\text { de Colletotrichum } \\
\text { gloeosporioides }\end{array}$ & Ativo & & \\
\hline & & & & $\begin{array}{l}\text { Germinação } \\
\text { do esporo de } \\
\text { Corynespora } \\
\text { cassiicola } \\
\end{array}$ & Ativo & & \\
\hline & & & & $\begin{array}{l}\text { Germinação } \\
\text { do esporo de } \\
\text { Colletotrichum } \\
\text { gloeosporioides }\end{array}$ & Ativo & & \\
\hline
\end{tabular}


TABELA 1. Atividades farmacológicas de diferentes extratos obtidos da Byrsonima verbascifolia Rich ex. A. Juss, avaliadas in vitro.

...continuação

\begin{tabular}{|c|c|c|c|c|c|c|}
\hline Folhas & Antimutagênica & Aquoso & 25,50 e $100 \mathrm{mg} / \mathrm{mL}$ & $\begin{array}{l}\text { Danos no DNA } \\
\text { induzidos pelo } \\
\text { antineoplásico } \\
\text { doxorubicina em } \\
\text { células somáticas } \\
\text { de Drosophila } \\
\text { melanogaster }\end{array}$ & $\begin{array}{l}\text { Ativo (preveniu os danos no DNA que } \\
\text { seriam induzidos pelo antineoplásico } \\
\text { doxorubicina) }\end{array}$ & $\begin{array}{l}\text { Mendanha } \\
\text { et al., } 2010\end{array}$ \\
\hline Folhas & Citotóxica & Aquoso & $\begin{array}{l}10 ; 20 ; 30 ; 40 ; 50 \\
60 ; 70 ; 80 ; 90 ; 100 \\
\text { e } 120 \mathrm{mg} / \mathrm{mL}\end{array}$ & $\begin{array}{l}\text { Quantidade de } \\
\text { adultos que emergem } \\
\text { de larvas de terceiro } \\
\text { estágio de Drosophila } \\
\text { melanogaster }\end{array}$ & Inativo (não apresentou efeito citotóxico) & $\begin{array}{l}\text { Mendanha } \\
\text { et al., } 2010\end{array}$ \\
\hline Folhas & Antiviral & Etanólico & 500 e $50 \mu \mathrm{g} / \mathrm{mL}$ & $\begin{array}{l}\text { Efeito citopático do } \\
\text { rotavírus em células } \\
\text { do rim de macaco } \\
\text { rhesus (MA-104) }\end{array}$ & Ativo (na concentração de $500 \mu \mathrm{g} / \mathrm{mL}$ ) & $\begin{array}{l}\text { Cecílio et } \\
\text { al., } 2012\end{array}$ \\
\hline Folhas & Citotóxica & Etanólico & $\begin{array}{l}5000,500 \text { e } 50 \\
\mu \mathrm{g} / \mathrm{mL}\end{array}$ & $\begin{array}{l}\text { Citotoxicidade em } \\
\text { células do rim de } \\
\text { macaco rhesus (MA- } \\
\text { 104) após } 48 \mathrm{~h} \text { de } \\
\text { incubação }\end{array}$ & $\begin{array}{l}\text { Inativo (induziu efeito citotóxico apenas } \\
\text { na concentração de } 5000 \mu \mathrm{g} / \mathrm{mL} \text { ) }\end{array}$ & $\begin{array}{l}\text { Cecílio et } \\
\text { al., } 2012\end{array}$ \\
\hline \multirow[t]{4}{*}{ Folhas } & \multirow[t]{4}{*}{ Antimutagênica } & \multirow[t]{4}{*}{ Hidroalcoólico } & \multirow[t]{4}{*}{$\begin{array}{l}0,013 \text { à } 2000 \mathrm{mg} / \\
\text { placa }\end{array}$} & $\begin{array}{l}\text { Teste de Ames } \\
\text { utilizando o } \\
\text { mutágeno 4-nitro-o- } \\
\text { fenilenodiamina }\end{array}$ & $\begin{array}{l}\text { Ativo (preveniu os danos no DNA que } \\
\text { seriam causados pelo mutágeno) }\end{array}$ & $\begin{array}{l}\text { Espanha et } \\
\text { al., } 2014\end{array}$ \\
\hline & & & & $\begin{array}{l}\text { Teste de Ames } \\
\text { utilizando o mutágeno } \\
\text { aflatoxina } B_{1} \text {, }\end{array}$ & $\begin{array}{l}\text { Ativo (preveniu os danos no DNA que } \\
\text { seriam causados pelo mutágeno) }\end{array}$ & \\
\hline & & & & $\begin{array}{l}\text { Teste de Ames } \\
\text { utilizando o mutágeno } \\
\text { benzo(a)pireno }\end{array}$ & $\begin{array}{l}\text { Ativo (preveniu os danos no DNA que } \\
\text { seriam causados pelo mutágeno) }\end{array}$ & \\
\hline & & & & $\begin{array}{l}\text { Teste de Ames } \\
\text { utilizando o mutágeno } \\
\text { mitomicina C }\end{array}$ & $\begin{array}{l}\text { Inativo (não preveniu os danos no DNA } \\
\text { que seriam causados pelo mutágeno) }\end{array}$ & \\
\hline Casca & Antifúngica & Metanólico & $10 \mathrm{mg} / \mathrm{mL}$ & $\begin{array}{l}\text { Bioautografia } \\
\text { com esporos de } \\
\text { Cladosporium } \\
\text { sphaerospermum }\end{array}$ & Inativo & $\begin{array}{l}\text { Alves et al., } \\
2000\end{array}$ \\
\hline Casca & Antifúngica & Aquoso & $10 \mathrm{mg} / \mathrm{mL}$ & $\begin{array}{l}\text { Bioautografia } \\
\text { com esporos de } \\
\text { Cladosporium } \\
\text { sphaerospermum }\end{array}$ & Inativo & $\begin{array}{l}\text { Alves et al., } \\
2000\end{array}$ \\
\hline \multirow[t]{4}{*}{ Casca } & \multirow[t]{4}{*}{ Antimicrobiana } & \multirow[t]{4}{*}{ Metanólico } & \multirow{4}{*}{$\begin{array}{l}5 \mathrm{mg} \text { do extrato } \\
\text { dissolvido no meio } \\
\text { de cultura }\end{array}$} & \multirow[t]{4}{*}{ Difusão em ágar } & Bacillus cereus & \multirow{4}{*}{$\begin{array}{l}\text { Alves et al. } \\
2000\end{array}$} \\
\hline & & & & & Escherichia coli & \\
\hline & & & & & Pseudomonas aeruginosa & \\
\hline & & & & & Staphylococcus aureus & \\
\hline \multirow[t]{4}{*}{ Casca } & \multirow[t]{4}{*}{ Antimicrobiana } & \multirow[t]{4}{*}{ Aquoso } & \multirow{4}{*}{$\begin{array}{l}5 \text { mg do extrato } \\
\text { dissolvido no meio } \\
\text { de cultura }\end{array}$} & \multirow[t]{4}{*}{ Difusão em ágar } & Bacillus cereus & \multirow{4}{*}{$\begin{array}{l}\text { Alves et al. } \\
2000\end{array}$} \\
\hline & & & & & Escherichia coli Inativo & \\
\hline & & & & & Pseudomonas aeruginosa Ativo & \\
\hline & & & & & Staphylococcus aureus & \\
\hline Casca & Moluscicida & Metanólico & $\begin{array}{l}\text { Concentração inicial } \\
\text { de } 100 \text { ppm }\end{array}$ & $\begin{array}{l}\text { Teste com } \\
\text { Biomphalaria } \\
\text { glabrata após } 24 \mathrm{~h} \text { de } \\
\text { exposição }\end{array}$ & Ativo & $\begin{array}{l}\text { Alves et al., } \\
2000\end{array}$ \\
\hline Casca & Moluscicida & Aquoso & $\begin{array}{l}\text { Concentração inicial } \\
\text { de } 100 \text { ppm }\end{array}$ & $\begin{array}{l}\text { Teste com } \\
\text { Biomphalaria } \\
\text { glabrata após } 24 \text { h de } \\
\text { exposição }\end{array}$ & Ativo & $\begin{array}{l}\text { Alves et al., } \\
2000\end{array}$ \\
\hline Casca & Tóxica & Metanólico & $1 ; 10 ; 100 \mu \mathrm{g} / \mathrm{mL}$ & $\begin{array}{l}\text { Teste de letalidade } \\
\text { utilizando Artemia } \\
\text { salina }\end{array}$ & Inativo (não apresentou toxicidade) & $\begin{array}{l}\text { Alves et al., } \\
2000\end{array}$ \\
\hline Casca & Tóxica & Aquoso & $1 ; 10 ; 100 \mu \mathrm{g} / \mathrm{mL}$ & $\begin{array}{l}\text { Teste de letalidade } \\
\text { utilizando Artemia } \\
\text { salina }\end{array}$ & Inativo (não apresentou toxicidade) & $\begin{array}{l}\text { Alves et al., } \\
2000\end{array}$ \\
\hline
\end{tabular}


TABELA 1. Atividades farmacológicas de diferentes extratos obtidos da Byrsonima verbascifolia Rich ex. A. Juss, avaliadas in vitro.

...continuação

\begin{tabular}{|c|c|c|c|c|c|c|c|}
\hline $\begin{array}{l}\text { Casca } \\
\text { da raiz }\end{array}$ & Citotóxica & Metanólico & $\begin{array}{l}\text { Concentração inicial } \\
\text { de } 2000 \mu \mathrm{g} / \mathrm{mL}\end{array}$ & $\begin{array}{l}\text { Monocamadas } \\
\text { de células Vero } \\
\text { cultivadas em } \\
\text { microplacas }\end{array}$ & Inativo (não apresentou e & feito citotóxico) & $\begin{array}{l}\text { Lopez et } \\
\text { al., } 2001\end{array}$ \\
\hline \multirow[t]{2}{*}{$\begin{array}{l}\text { Casca } \\
\text { da raiz }\end{array}$} & \multirow[t]{2}{*}{ Antiviral } & \multirow[t]{2}{*}{ Metanólico } & \multirow[t]{2}{*}{$\begin{array}{l}\text { Concentração inicial } \\
\text { de } 200 \mu \mathrm{g} / \mathrm{mL}\end{array}$} & \multirow[t]{2}{*}{$\begin{array}{l}\text { Concentração mínima } \\
\text { inibitória }\end{array}$} & $\begin{array}{l}\text { Vírus herpes simplex } \\
\text { tipo } 1\end{array}$ & Ativo & \multirow[t]{2}{*}{$\begin{array}{l}\text { Lopez et } \\
\text { al., } 2001\end{array}$} \\
\hline & & & & & Poliovírus & Inativo & \\
\hline \multirow{8}{*}{$\begin{array}{l}\text { Casca } \\
\text { da raiz }\end{array}$} & \multirow[t]{8}{*}{ Antimicrobiana } & \multirow[t]{8}{*}{ Metanólico } & \multirow[t]{8}{*}{$100 \mathrm{mg} / \mathrm{mL}$} & \multirow[t]{8}{*}{ Teste de disco-difusão } & Bacillus subtilis & Ativo & \multirow{8}{*}{$\begin{array}{l}\text { Lopez et } \\
\text { al., } 2001\end{array}$} \\
\hline & & & & & Streptococcus faecalis & Ativo & \\
\hline & & & & & $\begin{array}{l}\text { Staphylococcus aureus } \\
\text { K147 meticilina-sensivel }\end{array}$ & Ativo & \\
\hline & & & & & Escherichia coli DC10 & Inativo & \\
\hline & & & & & Klebsiella pneumoniae & Inativo & \\
\hline & & & & & $\begin{array}{l}\text { Pseudomonas } \\
\text { aeruginosa } 187\end{array}$ & Inativo & \\
\hline & & & & & Salmonella typhimurium & Inativo & \\
\hline & & & & & Mycobacterium phlei & Ativo & \\
\hline $\begin{array}{l}\text { Casca } \\
\text { da raiz }\end{array}$ & Antifúngica & Metanólico & $100 \mathrm{mg} / \mathrm{mL}$ & Teste de disco-difusão & Candida albicans & Inativo & $\begin{array}{l}\text { Lopez et } \\
\text { al., } 2001\end{array}$ \\
\hline $\begin{array}{l}\text { Polpa } \\
\text { do fruto }\end{array}$ & Antioxidante & Hidroacetônico & $\begin{array}{l}0,50 ; 1 \text { e } 1,50 \text { mg/ } \\
\mathrm{mL}\end{array}$ & $\begin{array}{l}\text { Captura dos radicais } \\
\text { DPPH e ABTS, } \\
\text { redução do íon férrico } \\
\text { e sistema } \beta \text {-caroteno/ } \\
\text { ácido linoléico }\end{array}$ & Ativo & & $\begin{array}{l}\text { Morais et } \\
\text { al., } 2013\end{array}$ \\
\hline
\end{tabular}

TABELA 2. Atividades farmacológicas do extrato de Byrsonima verbascifolia Rich ex. A. Juss avaliadas in vivo.

\begin{tabular}{|c|c|c|c|c|c|c|}
\hline $\begin{array}{l}\text { Parte } \\
\text { usada }\end{array}$ & Atividade avaliada & Extrato & Dose & Modelo & Resultado & Referência \\
\hline Folhas & Teratogênica & Hidrometanólico & $\begin{array}{l}50 \mathrm{mg} / \\
\mathrm{Kg}\end{array}$ & $\begin{array}{l}\text { Desenvolvimento embrio- } \\
\text { fetal em camundongos } \\
\text { Swiss fêmeas (grávidas) } \\
\text { com administração via oral }\end{array}$ & $\begin{array}{l}\text { Não apresentou efeito } \\
\text { teratogênico }\end{array}$ & $\begin{array}{l}\text { Gonçalves et } \\
\text { al., } 2013\end{array}$ \\
\hline Folhas & Mutagênica & Hidrometanólico & $\begin{array}{l}50 \mathrm{mg} / \\
\mathrm{Kg}\end{array}$ & $\begin{array}{l}\text { Teste do micronúcleo } \\
\text { em sangue periférico } \\
\text { de camundongos Swiss } \\
\text { fêmeas (grávidas) e } \\
\text { machos com administração } \\
\text { via oral }\end{array}$ & $\begin{array}{l}\text { Não induziu } \\
\text { mutagenicidade }\end{array}$ & $\begin{array}{l}\text { Gonçalves et } \\
\text { al., } 2013\end{array}$ \\
\hline Folhas & Imunomodulatória & Hidrometanólico & $\begin{array}{l}50 \mathrm{mg} / \\
\mathrm{Kg}\end{array}$ & $\begin{array}{l}\text { Análise de fagocitose } \\
\text { esplênica em camundongos } \\
\text { Swiss fêmeas (grávidas) e } \\
\text { machos com administração } \\
\text { via oral }\end{array}$ & $\begin{array}{l}\text { Não apresentou } \\
\text { efeito estimulante ou } \\
\text { depressor sobre o } \\
\text { sistema imune }\end{array}$ & $\begin{array}{l}\text { Gonçalves et } \\
\text { al., } 2013\end{array}$ \\
\hline
\end{tabular}

\section{REFERÊNCIAS}

AGRA, M.F. Contribuição ao estudo das plantas medicinais na Paraíba. Ciência e Cultura, v.33, p.64-66, 1982.

ALBERTO, P.S. et al. Methods to overcome of the dormancy in murici (Byrsonima verbascifolia) seeds. Semina: Ciências Agrárias, v.32, n.3, p.1015-1020, 2011.

ALMEIDA, S.P. et al. Cerrado: Espécies Vegetais Úteis. 1. ed. Planaltina: EMBRAPA-CPAC, 1998, 464 p.

ALVES, T.M.A. et al. Biological Screening of Brazilian Medicinal Plants. Memórias do Instituto Oswaldo
Cruz, v.95, n.3, p.367-373, 2000.

ANDRADE, I. et al. A lagarta de Cerconota achatina (Zeller) (Leptidoptera, Oecophoridae, Stenomatinae): biologia e ocorrência em plantas hospedeiras do gênero Byrsonima Rich (Malpighiaceae). Revista Brasileira de Zoologia, v.12, n.4, p.735-741, 1995.

ANDRADE, l. et al. Richness and abundance of caterpillars on Byrsonima (Malpighiaceae) species in an area of cerrado vegetation in Central Brazil. Revista de Biologia Tropical, v.47, n.4, 1999.

ARAÚJO, R.R. et al. Caracterização biométrica de 
frutos e sementes de genótipos de murici (Byrsonima verbascifolia (L.) Rich) do tabuleiro costeiro de Alagoas. Revista Caatinga, v.22, n.3, p.224-228, 2009.

BARBOSA, R.I. et al. Notas sobre a composição arbóreoarbustiva de uma fisionomia das savanas de Roraima, Amazônia Brasileira. Acta Botanica Brasilica, v.19, n.2, p.323-329, 2005.

BARBOSA, R.I.; FEARNSIDE, P.M. Wood density of trees in open savannas of the Brazilian Amazon. Forest Ecology and Management, v.199, p.115-123, 2004.

BARCELOS, C.C. et al. Efeitos neuromusculares in vitro e in vivo do atracúrio e do rocurônio em ratos submetidos a tratamento de sete dias com carbamazepina. Revista Brasileira de Anestesiologia, v.58, n.2, p.137-151, 2008.

BRASIL. Ministério da Saúde. Secretaria de Ciência, Tecnologia e Insumos Estratégicos. Departamento de Assistência Farmacêutica. Política Nacional de Plantas Medicinais e Fitoterápicos. Brasília: Ministério da Saúde, 2006. p. 60.

CECÍLIO, A.B. et al. Screening of Brazilian medicinal plants for antiviral activity against rotavirus. Journal of Ethnopharmacology, v.141, p.975-981, 2012.

COON, J.S.T.; ERNST, E. Herbs for serum cholesterol reduction: a systematic review. The Journal of Family Practice, v.52, n.6, p.468-78, 2003.

ESPANHA, L.G. et al. Mutagenicity and antimutagenicity of six Brazilian Byrsonima species assessed by the Ames test. Complementary and Alternative Medicine, v.14, n.182, p.1-10., 2014.

FALCÃO, H.S. et al. Review of the plants with antiinflammatory activity studied in Brazil. Revista Brasileira de Farmacognosia, v.15, n.4, p.381-391, 2005.

GONÇALVES, C.A. et al. Gestational exposure to Byrsonima verbascifolia: Teratogenicity, mutagenicity and immunomodulation evaluation in female Swiss mice. Journal of Ethnopharmacology, v. 150, p.843850, 2013.

GOTTLIEB, O.R. et al. Triterpenoids from Byrsonima verbascifolia. Phytochemistry, v.14, n.5, p.1456-56, 1975.

GUILHON-SIMPLICIO, F.; PEREIRA, M.M. Aspectos químicos e farmacológicos de Byrsonima (Malpighiaceae). Química Nova, v.34, n.6, p.10321041, 2011.

GUIMARÃES, M.M.; SILVA, M.S. Valor nutricional e características químicas e físicas de frutos de murici-passa (Byrsonima verbascifolia). Ciência e Tecnologia de Alimentos, v.28, n.4, p.817-821, 2008.

HAMACEK, F.R. et al. Murici, fruit from the Cerrado of Minas Gerais, Brazil: physical and physicochemical characteristics, and occurence and concentration of carotenoids and vitamins. Fruits, v.69, n.6, p.459-72, 2014.

LOPEZ, A. et al. Antiviral and antimicrobial activities of Colombian medicinal plants. Journal of Ethnopharmacology, v. 77, p.189-196, 2001.

MABBERLEY, D. J. The Plant-Book: A portable dictionary of the higher plants. 4.ed. New York: Cambridge University Press, 1993. 520 p.

MENDANHA, D.M. et al. Modulatory effect of Byrsonima verbascifolia (Malpighiaceae) against damage induced by doxorubicin in somatic cells of Drosophila melanogaster. Genetics and Molecular Research, v.9, n.1, p.69-77, 2010.

MENGUE, S.S. et al. Uso de plantas medicinais na gravidez. Revista Brasileira de Farmacognosia, v.11, n.1, p.21-35, 2001.

MOLL, M.C.N. Antihiperlipemiantes de origen vegetal. Revista de Fitoterapia, v.6, n.1, p.11-26, 2006.

MORAIS, M.L. et al. Determinação do potencial antioxidante in vitro de frutos do cerrado brasileiro. Revista Brasileira de Fruticultura, v.35, n.2, p.355360, 2013.

NARUZAWA, E.S.; PAPA, M.F.S. Antifungal activity of extracts from brazilian Cerrado plants on Colletotrichum gloeosporioides and Corynespora cassiicola. Revista Brasileira de Plantas Medicinais, v.13, n.4, p.408412, 2011.

NASCIMENTO, A.R.; PENTEADO-DIAS, A.M. New species of Chelonus (Microchelonus) Szépligeti, 1908 (Hymenoptera: Braconidae: Cheloninae) from Brazil. Brazilian Journal of Biology, v.71, n.2, 2011.

PANIZZA S. Plantas que Curam: Cheiro de Mato. 3. ed. São Paulo: IBRASA, 1998, 279 p.

RIBEIRO, J.E.L. et al. Flora da Reserva Ducke: Guia de identificação das plantas vasculares de uma floresta de terra firme na Amazônia Central. 1.ed. Manaus: INPA, 1999. 816 p.

SANNOMIYA, M. et al. Flavonoids and antiulcerogenic activity from Byrsonima crassa leaves extracts. Journal of Ethnopharmacology, v.97, n.1, p.1-6, 2005.

SOUZA, V.C.; LORENZI, H. Botânica sistemática: guia ilustrado para identificação das famílias de fanerógamas nativas e exóticas no Brasil, baseado em APG II. 2.ed. Nova Odessa: Instituto Plantarum, 2008. 704 p.

WANG, H.X.; NG, T.B. Natural products with hypoglycemic, hypotensive, hypocholesterolemic, antiatherosclerotic and antithrombotic activities. Life Sciences, v.65, n.25, p.2663-77, 1999.

YUNES, R.A. et al. Fármacos e fitoterápicos: a necessidade do desenvolvimento da indústria de fitoterápicos e fitofármacos no Brasil. Química Nova, v.24, n.1, p.147-152, 2001.

Rev. Bras. PI. Med., Campinas, v.17, n.4, supl. II, p.1000-1006, 2015. 